\title{
Erratum to: Changes of Serum Insulin-like Growth Factor-2 Response to Negative Symptom Improvements in Schizophrenia Patients Treated with Atypical Antipsychotics
}

\author{
Xue-lin $\mathrm{CHAO}^{1}$, Shu-zhen JIANG ${ }^{2}$, Jian-wen XIONG ${ }^{3}$, Jin-qiong ZHAN ${ }^{2}$, Bo WEI ${ }^{2,3}$, Chun-nuan $\mathrm{CHEN}^{4}$, Yuan-jian YANG ${ }^{2,3}$ \\ ${ }^{1}$ Department of Psychosomatic Medicine, The First Affiliated Hospital of Nanchang University, Nanchang 330006, China \\ ${ }^{2}$ Biological Psychiatry Laboratory, Jiangxi Mental Hospital/Affiliated Mental Hospital of Nanchang University, Nanchang \\ 330029, China \\ ${ }^{3}$ Department of Psychiatry, Jiangxi Mental Hospital/Affiliated Mental Hospital of Nanchang University, Nanchang 330029, \\ China \\ ${ }^{4}$ Department of Neurology, The Second Clinical Medical College, The Second Affiliated Hospital, Fujian Medical University, \\ Quanzhou 362000, China
}

(C) The Author(s) 2020

Current Medical Science

https://link.springer.com/article/10.1007/s11596-020-2214-0

40(3):563-569,2020

\begin{abstract}
The article "Changes of Serum Insulin-like Growth Factor-2 Response to Negative Symptom Improvements in Schizophrenia Patients Treated with Atypical Antipsychotics", written by Xue-lin CHAO, Shu-zhen JIANG, Jian-wen XIONG, Jin-qiong ZHAN, Bo WEI, Chun-nuan CHEN, Yuan-jian YANG was originally published electronically on the publisher's internet portal on June 2020 without open access. With the author(s)' decision to opt for Open Choice, the copyright of the article is changed to (C) The Author(s) 2020 and the article is forthwith distributed under a Creative Commons Attribution 4.0 International License (https://creativecommons.org/licenses/by/4.0/), which permits use, sharing, adaptation, distribution and reproduction in any medium or format, as long as you give appropriate credit to the original author(s) and the source, provide a link to the Creative Commons license, and indicate if changes were made.
\end{abstract}

The original article has been corrected.

Corresponding authors: Chun-nuan CHEN, Yuan-jian YANG 